development of these semi-conductor detectors is directed particularly at establishing production methods and finding ways of making larger detectors.

Basic nuclear research is being carried out with the riew of improving the imperfect understanding of the arrangement of the constituent particles within nuclei and of the forces that hold them together. Work has continued at Harwell on the nature and properties of radioactive aerosols, with particular attention being directed to iodine. A new laboratory designed specifically for remotely controlled experiments of plutonium critical assemblies came into use at Dounreay, and considerable progress was made at the Culham Laboratory site where the objective is the generation of power from fusion reactions. In the extensive research in plasma physics, the key problem is the stability of the plasma and magnetic field system, and the emphasis of the experimental work is on those systems of magnetic confinement thought theoretically to be stable.

\title{
THE GHANA SCIENCE ASSOCIATION
}

$\mathrm{T}$ HE Ghana Science Association held its second annual congress during June 28-July 1, at the University of Ghana. The highlight of the conference, the start of which coincided with the ending of the Accra assembly on "The World Without the Bomb", was the participation of a number of scientists from various other countries who were in Ghana for the Accra Assembly. The visiting scientists had been informed of this meeting before their arrival in Ghana, and some of them read papers to the Association during the conference, including: Prof. J. D. Bernal (United Kingdom), Prof. Ivan Supek (Yugoslavia), Prof. Gerd Burkhardt (West Ger. many), Sir Robert Watson-Watt (U.S.A.), Prof. Alexjandro Lipschutz (Chile) and Dr. H. Marcovich (France).

The Ghana Science Association is a body in Ghana which is devoted solely to encouraging scientific and technological research and advancing both the understanding and teaching of science. To this end, the Association provides a forum for scientists working in Ghana and guests from outside. It also serves as a medium for informing the public of the part which science and technology are playing and can continue to play in the development of Ghana.

The second annual congress was opened by the Minister Responsible for the National Research Council of Ghana, Mr. Kofi Baako, who deputized for Osagyefo Dr. Kwame Nkrumah, who is president of the Ghana Academy of Sciences-Prof. J. D. Bernal having given a pre-conference open lecture on June 22 on "The Origin of Life". In his opening address, the Minister recognized that science was no magic wand with which to convert poor deserts to rich fertile lands, but that hard work was what was needed in all scientific endeavours. The presidential address was given this year by Dr. S. R. A. Dodu. In his speech, which set a high standard, Dr. Dordu traced in outline the stages of development in the history of medicine. $\mathrm{He}$ observed that contemporary primitive practices are often just echoing fragments of the past activities of pre-scientific man, and that by means of science we are able to dissipate superstitions and fears based on ignorance and to evaluate and assess the traditions and inherited customs by which we habitually order our lives and finally shape the very destiny of mankind.

Later that evening, Dr. H. Marcovich, of the Pastour Instituto in Paris, gave an open lecture, the topic of which was, "Small Doses of Radiation, What are Their Biological Effects?". In his lecture, Dr. Marcovich produced evidence to question the assumption in some quarters that small doses of radiation had no biological effects of any significance.
There were two full sessional days, namely, June 29 and 30 , and on each there were two morning sessions and one afternoon session, each session consisting of three papers. The evenings were taken up by some open items.

The first morning session on June 29 was under the chairmanship of Dr. P. M. J. Phillips, deputy chief medical officer. It was devoted to subjects of medical importance such as "Drugs and the Organization of Mind", by Dr. A. C. Mundy-Castle of the National Institute of Health and Medical Research, Accra; "Age and Tuberculosis Morbidity", by Dr. E. Laing of the Department of Botany, University of Ghana; and "Structure and Activity of the Steroid Hormones", by Prof. J. A. K. Quartey of the Department of Chemistry, University of Ghana. The first of these papers aroused great interest, and the speaker dealt with the varied characteristic disturbances evoked in humans by certain drugs and the investigations being carried out on the biochemical origin of madness. $\mathrm{He}$ also showed cases where similar dis. turbances were induced without resort to chemicals. In Dr. Laing's paper an analysis of variance carried out on tuberculosis morbidity data in parts of Ghana showed a significant positive regression of morbidity with age. Prof. Quartey traced some of the chemical probloms encountered in obtaining hormone substitutes in sufficient quantities for clinical hormone therapy, in particular that of determining the required structural features of the steroid molecule.

The second morning session concerned some aspects of agricultural research, under the chairmanship of K. A. Quagraine, chief scientific officer. The first in this series was a paper by $O$. Snow, adviser on agricultural matters to the Ministry of Agriculture. on "The Economics of Agricultural Research". Recognizing that research is one item in the cost of production, Mr. Snow considered, in an exploratory fashion, the problem in Ghana as to how much money can justifiably be spent on agricultural research, with the provisos that the research is well guided, gives results and is efficiently utilized. The second speaker was P. Ahn of the Faculty of Agriculture, University of Ghana, who read his papor on "Climate, Soils and Agriculture in the Forest Zone" (of Ghana). He showed in an elegant manner how the differences in rainfall in various parts of the forest \%one are related to differences in the type of forest, both in floristic composition and in structure, and also to important differences in the soils. The speaker emphasized that. as a result, both soils and natural vegetation can be correlated with agricultural belts. The final paper in the series, on "Land Capability Classification of the Soils of Ghana", was read by Mr. H. B. Obeng 
and Mr. G. K. Smith, both of the Scientific Services Division of the Ministry of Agriculture. The paper attempted to make a preliminary classification of the soils of Ghana under seven capability classes. The classification, which is based on the American system, involves a critical evaluation of a number of important soil characteristics and the degree of limitation of each soil to mechanized farming and management. It aimed at ensuring proper use of land and efficient crop and livestock production. From the discussion that followed this excellent attempt, it became obvious that the scheme would have to be modified when more results became available concerning soils in Ghana.

The afternoon session, under the chairmanship of Dr. J. Yanney-Wilson of the Department of Botany, University of Ghana, consisted of a mixed bag of topics. The first speaker, H. R. B. A. Prempeh, acting regional agricultural officer for the Eastern Region, read a paper on "Improvement of Poultry in Ghana by Progeny Testing". He called for a programme by which the small number of imported birds which have been able to maintain their high breeding values could be 'progeny-tested' to form a foundation stock. Dr. J. D. Thomas, senior lecturer in zoology, University of Ghana, next gave his paper on "A Preliminary Account of the Life-cycle of Mesocoelium monodi (a trematode)". This parasite is widely distributed in West Africa and elsewhere in the tropical belt, and could be used as type specimen in tropical schools. The last speaker was Dr. O. Davies, roader in archæology at the University of Ghana, and his topic was "The Stone Age in West Africa". The speaker, who is well known for his work in this field, gave a general account of the stone-age cultures in West Africa south of the Niger-Senegal, and showed a number of specimens that he had collected.

There were two open items later that evening. Prof. Ivan Supek, professor of theoretical physics and philosophy at the University of Zagreb, spoke on "Science, Philosophy and Art", and after supper there was a symposium on "The Hopes and Dangers of Atomic Energy", under the chairmanship of Sir Robert Watson-Watt.

The second sessional day, June 30, commenced with the first morning session which was devoted to physics. Under the chairmanship of Prof. A. Nunn May of the Department of Physics, University of Ghana, the session started with a paper by Prof. Gerd Burkhardt of the Institute of Theoretical Physics, Hanover, West Germany. He spoke on "Some Aspects of Plasma-Physies". Prof. Burkhardt stated that the great interest now shown in research concerning the plasma-state of matter stems from the problem of controlling thermo-nuclear reaction. The long-range forces between charged particles which make the kinetic behaviour of a plasma different from that of a neutral gas give rise to difforent modes of wave propagation, characteristic of a plasma; he then showed how these spaco charge waves could excite electromagnetic waves which are observed from the Sun and other cosmic bodies in the radio-frequency range. The next paper was on "Atomic Reactor Research in Ghana", by Dr. A. H. Ward of the Radio-Isotope Research Unit at Legon. He gave a simple explanation of the construction and operation of reactors in general and, in particular, the $V V R-C$ tank-type, and ended with an evaluation of the proposed $2,000 \cdot \mathrm{kW}$ research reactor for Ghana in the light of its timing in the general development plans of Ghana, the capabilities of the reactor and its cost, including the problem of highly trained personnel. The final speaker in the series was Father J. R. Koster of the Department of Physics, University of Ghana, who read a paper on "Some Recent Scientific Applications of the Doppler Shift". With illustrations of tape recordings, Father Koster showed how Doppler shift techniques are now being applied to some recent problems in ionospheric studies and satellite location.

The second morning session, with Prof. Hugh Nicol as chairman, had a zoological bias. G. C. Rawson and J. N. N. Adjetey, fisheries officers at Tema, read a paper on "The Development of Fishery Resources" in which they emphasized the need to tackle fisheries development from the aspects of biology, technology and economics. E. A. Kwei, also a fisheries officer at Tema, read a paper on "The Spawning Migration of Sardinella aurita (Val.)". He showed that the appearance of this very important fish near the shore coincided with its spawning, which thus has effect on the fishing season in Ghana. Finally, W. Pople of the Zoology Department, University of Ghana, gave a paper on "The Annual Cycle of a Lagoon in Ghana". He pointed out the features of the small blind estuaries of Ghana and described the annual foatures of the Kpeshi Lagoon of Accra.

The afternoon session was chaired by $\mathrm{O}$. Snow, adviser on agricultural matters. Dr. W. K. Agble, deputy chief scientific officer, spoke on "Improvement of the Yields of Maize in Ghana". He reviewed the work done in this field since the adoption of a breeding programme on conventional lines as well as on emergent concepts of breeding tropical maize leading to the development of new synthetic hybrid maizes. The next paper was that of Dr. K. Kadambi, formerly of the Indian Forestry Service, whose paper was read in his absence by Dr. B. J. Harris. It was on "Vegetative Propagation of Tropical Plants by Means of Air-layers". Finally, in this series was a paper by P. Appiagyei-Danka of the Scientific Services Division on "Porosity Status of Some Major Soils of Ghana". The paper gave in much detail original investigations carried out by P. AppiagyeiDanka on this vital aspect of the soil, and provided information that is much needed with the introduction of mechanization and intensive cropping throughout Ghana.

The sessions for the day and for the whole conference were rounded off with a special short session of two papers read by two of the visiting scientists. The first speaker was the 80 -year-old Chilean experimental physiologist, Prof. Alexjandro Lipschutz, who read a paper on "Some Progress with Hormones in Cancer Research-Experimental Aspects". The final speaker was Sir Robert Watson-Watt, who read a paper on "The Ethical Responsibilities of the Scientist". In the evening there was a film show.

The final day of the conference, July 1, was devoted to excursions to Tema, Akosombo and Nungua Station. The conference was rounded off with the annual dinner of the Association in the evening.

There is no doubt that the second annual congress constitutes an improvement over the first one in many ways, particularly in respect of the participation of a number of leading scientists from other parts of the world. Most of the papers read at the congress are to be published in the fortheoming issues of the Ghana Journal of Science.

J. YANNTY-WITSON 